\title{
Antioxidant, Anticancer Activity, and Other Health Effects of a Nutritional Supplement (Galaxy ${ }^{\circledR}$ )
}

\author{
Gary M. Booth, Tory L. Parker and Christopher M. Lee
}

Additional information is available at the end of the chapter

http://dx.doi.org/10.5772/51250

\section{Introduction}

Approximately one in four prescription drugs from pharmacies in the U.S., Canada, and Western Europe have active ingredients that are plant derived (Balick and Cox, 1997). Edible and even non-edible plants have long been considered sources of anticancer drugs. Indeed, our laboratory (Dr. Booth) published a paper two years ago (Capua et al., 2010) showing that even non-edible and non-tropical desert plants have bioactivity against a wide variety of human cancer cells. From the literature, it is clear that diets rich in grains, fruits, and vegetables are known to reduce cancer risk (Ferguson, et al., 2004; Guthrie and Carrol, 1998) especially those rich in antioxidant activity.

Over the last 20 years, a number of juices and nutritional liquid supplements have appeared on the market purporting high amounts of antioxidant activity and suggesting a number of benefits to human health. In the corridor of Utah Valley, for example, there are at least a dozen manufacturing centers for plant-derived supplements within 50 miles of each other. While these supplements have caught the interest of health enthusiasts throughout the world, it is of interest that very few toxicology studies have been published on these supplements especially with reference to anticancer dose-response curves and antioxidant activity. Three years ago, our laboratory was asked to evaluate the potential health effects of a new nutritional supplement referred to as Galaxy®. This product was of interest to us because it contained a variety of bioactive ingredients including several superfruits (a marketing term for fruits with unusual nutrient and antioxidant properties).

We agreed to investigate this product on five conditions:

1. We develop our own research protocols. 
2. Principal investigators accept no personal compensation for the studies.

3. We were allowed to present our data at professional conferences and symposia.

4. We are allowed to publish our results (regardless of the outcome) in the peer-reviewed literature.

5. They provide the product to our lab free of charge.

The company agreed without hesitation which was a fresh departure from the traditional position of the industry that generally requires non-disclosure documents, no-publication policies, and restricted professional presentations of the data sets. Thus, with that agreement, we pressed forward with the following objectives:

1. Investigate the antioxidant activity of the freeze-dried product.

2. Develop dose-response curves using Galaxy ${ }^{\circledR}$ on a variety of human cancer cell lines including calculation of EC50s.

3. Determine if a correlation exists between anticancer activity and antioxidant activity using Galaxy ${ }^{\circledR}$ and several selected superfruits.

4. Compare the toxicity of an approved FDA drug (paclitaxel) with the particulate (most active) fraction of Galaxy®.

5. Develop Bioactivity Indices for Galaxy ${ }^{\circledR}$ and selected superfruits.

6. Develop Selectivity Indices which compares the cytotoxicity between cancer cells and normal cells.

7. Show the effect of Galaxy® on blood glucose levels of senior athletes ( $n=308)$.

8. Demonstrate the effect of Galaxy ${ }^{\circledR}$ on the white blood cell (WBC) count of an acute lymphocytic leukemia (ALL) patient over a number of months without chemotherapy or any other treatment intervention.

9. Determine the simple carbohydrate and amino acid content of a freeze-dried sample of Galaxy®.

\section{Materials and methods}

Galaxy, a nutritional supplement, was provided by JoyLife International. This blend contains 32 bioactive ingredients. Bioassay data from this product were collected using the straight sample (from the container), as a freeze-dried sample (Fig. 1), supernatant, or particulate fraction. Bioassay procedures for all these matrices were completed using methods developed previously from Brigham Young University (BYU) laboratories (Capua et al., 2010).

All cell lines were grown in the laboratories of BYU or Reaction Biology Corporation. The purity of the cell lines was checked periodically using an inverted microscope (Fig. 2).

The ORAC assay was performed according to published protocols (Parker et al., 2007; Fig. 3). Preparation of the freeze-dried Galaxy sample for sugar extraction was completed by extracting $5 \mathrm{~g}$ of the sample with $50 \mathrm{~mL}$ of $70 \%(\mathrm{w} / \mathrm{v})$ methanol solution in a $100 \mathrm{~mL}$ Ehrlenmeyer Flask for 24 hours using a stirring bar. The extract was then analyzed for sugars and amino acids standardized GC/MS procedures from protocols developed at the BYU College of Life Sciences Chromatography Facility. 


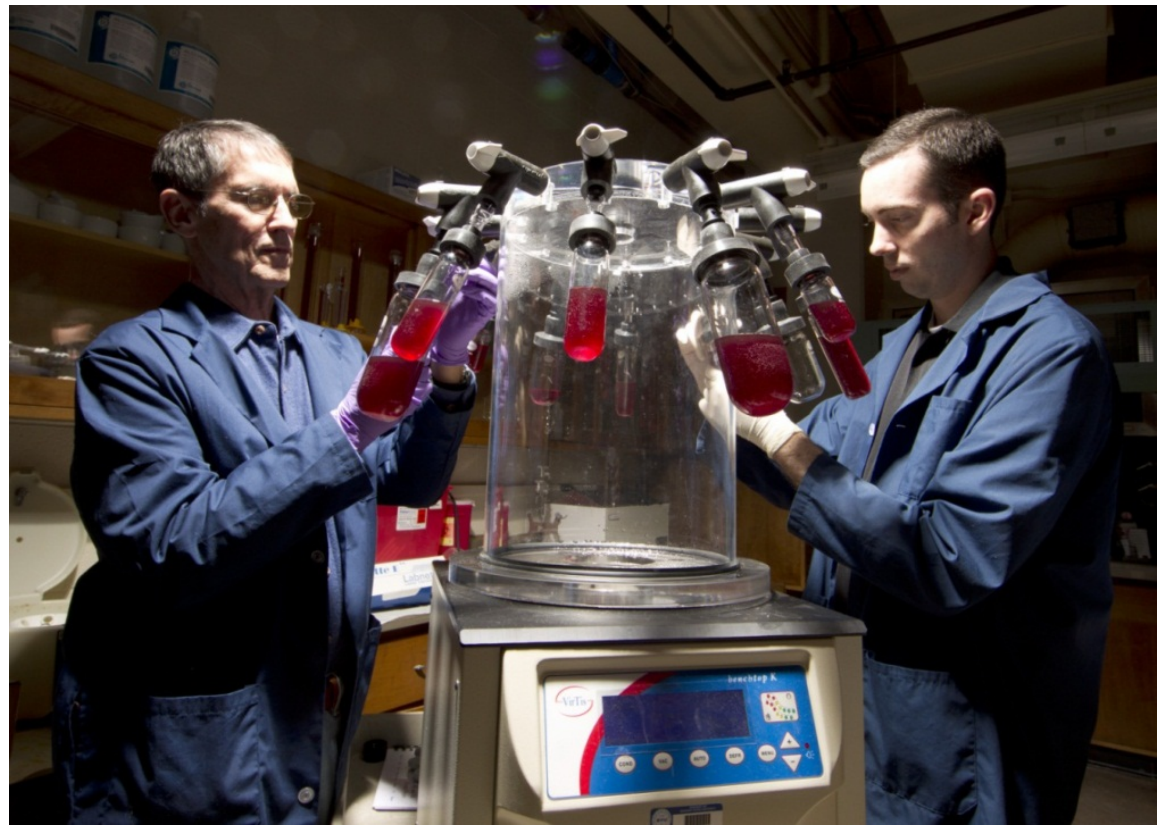

Figure 1. Dr. Gary M. Booth (left) and Kyle Lorenzen preparing freeze-dried samples of Galaxy®.

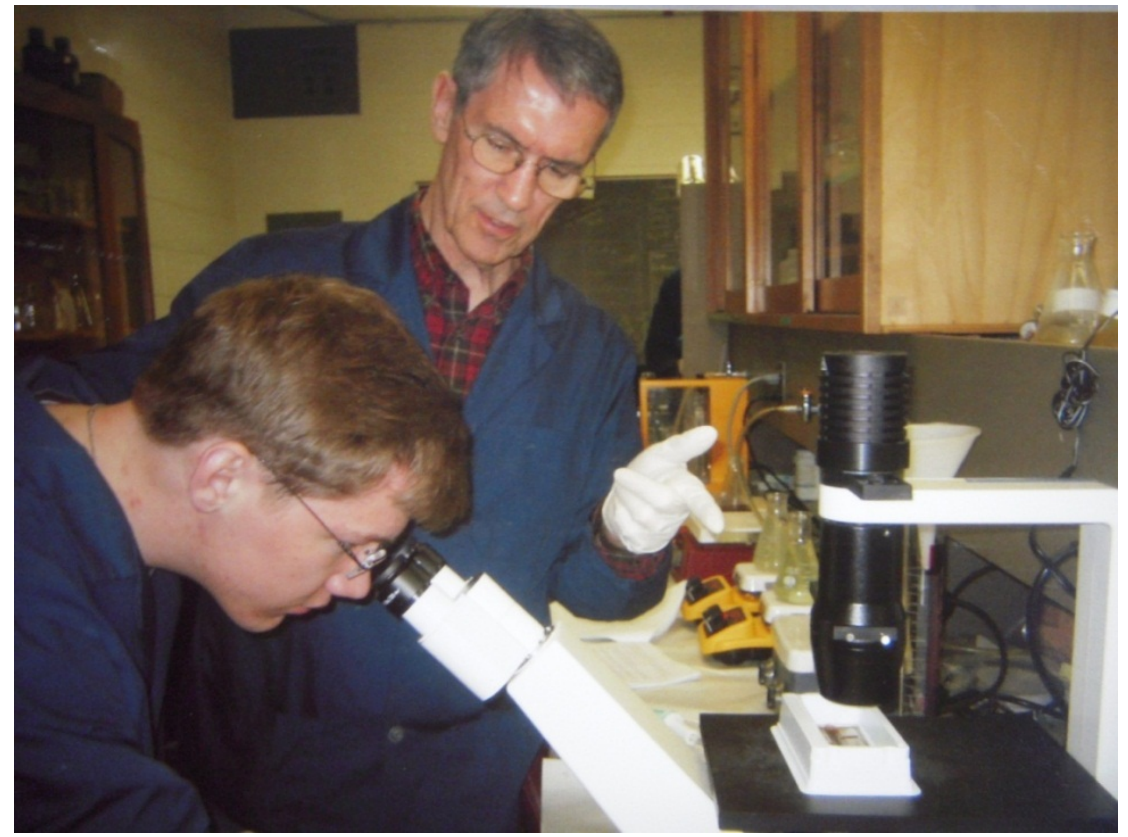

Figure 2. Dr. Gary M. Booth (standing) and Matt Dungan viewing the effect of Galaxy® on cancer cells in an inverted microscope. 


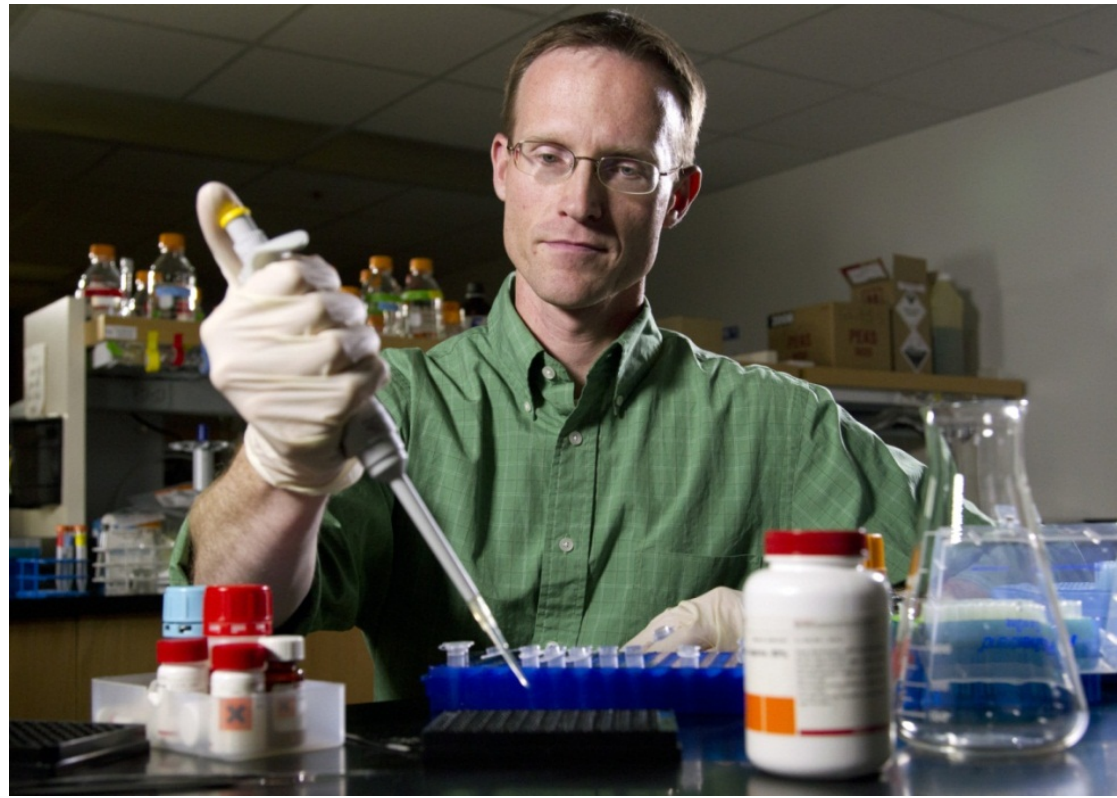

Figure 3. Dr. Tory L. Parker preparing Galaxy® samples for determination of oxygen radical absorption capacity (ORAC).

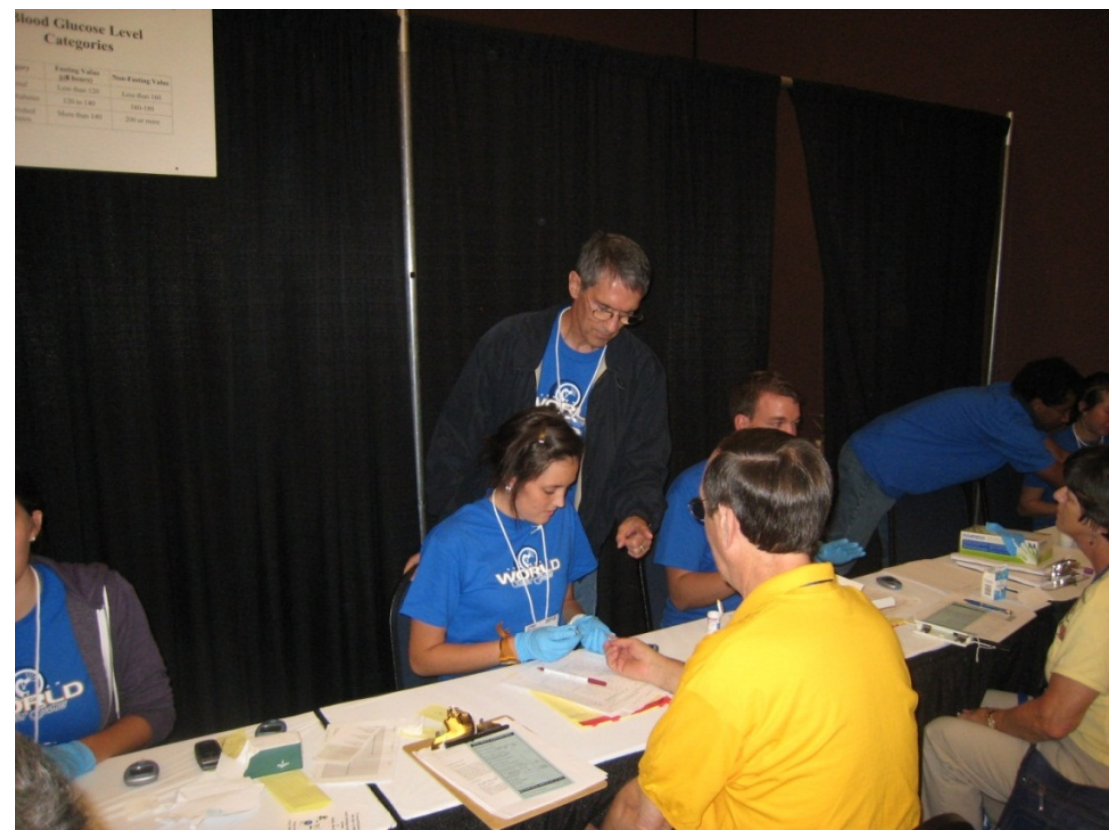

Figure 4. Collection of blood glucose samples from the athletes $(n=308)$ of the 2011 Huntsman Senior World Games for investigation of the effect of Galaxy® on blood glucose. 
Glucose measurements were determined using a Bayer Contour Glucosometer on 308 senior athletes during the 2011 Huntsman Senior Games held in St. George, Utah. The average age of the participants was $64.5 \pm 4$ years (Fig 4 ).

Onxol® (paclitaxel; also called Taxol ${ }^{\circledR}$ ) an FDA-approved drug for breast cancer was purchased from Cancer Care Northwest in Spokane, WA. This drug was used to compare with the most active fraction (particulate) of Galaxy®.

\section{Results and discussion}

It is now well documented through epidemiological studies that diets rich in fruits and vegetables can reduce cancer and other chronic diseases (Boivin et al., 2007; Block et al., 1992; Steinmetz et al., 1991). It is believed that the reduction in these chronic diseases is related to the diversity and high concentrations of antioxidants, known collectively as phytochemicals. Furthermore, it has been generally documented that the complex mixtures of phytochemicals in fruits and vegetables are more effective than their individual components in preventing cancer through a variety of mechanisms that include both additive and synergistic effects (Liu et al., 2004; Seeram et al., 2005; Mertens-Talcon et al., 2003; Zhou et al., 2003).

In the U.S., a recent survey (Yang et al., 2011) showed that the total antioxidant capacity (TAC) was positively correlated with daily consumption of fruits and fruit juices, vegetables, and antioxidant-containing beverages. The major sources of the dietary TAC in the U.S. were teas, dietary supplements, and fruits and fruit juices which accounted for $28 \%, 25 \%$, and $17 \%$ of the TAC respectively. Unfortunately, vegetables only contributed $2 \%$ of the dietary TAC. Recognizing that their diets may not be optimum, many people supplement their diet with powdered or liquid supplements, such as Galaxy ${ }^{\circledR}$ to get their "daily dose" of dietary TAC.

The nutritional supplement/juice industry has shown consistent growth over the last several years, mostly through consumption by the older generation. However, even though this economic growth spurt has stimulated the economy and possibly even contributed to the health of our population, the supporting scientific data from these products has often been lacking. The experimental data from this product now follows:

A freeze dried sample of Galaxy ${ }^{\circledR}$ had an ORAC value of $178.10 \pm 15.02 \mu$ moles TE/g $(n=4)$, while the fresh product was $35.6 \pm 3.1 \mu$ moles TE/g wet weight. The USDA recommends (USDA, 1999) that each person consumes approximately 3000-5000 ORAC units per day. As of this writing, the average person in the U.S. consumes less than 1000 ORAC units/day. Based on our data (200 mg particulates/one mL Galaxy $\left.{ }^{\circledR}\right)$ ), if a person consumes $30 \mathrm{~mL}$ of Galaxy ${ }^{\circledR}$ per day, they would consume about 1068 ORAC units per day or $21-36 \%$ of the recommended units per day. And if one consumes it $2 X /$ day, the values double, or $42-72 \%$ of the recommended units. Thus, one bottle of Galaxy ${ }^{\circledR}$ contains about 26,715 ORAC units using the freeze-dried data or 26,700 ORAC units if the fresh weight data are used. Thus, Galaxy ${ }^{\circledR}$ juice from the bottle has a higher ORAC value than 21 of the 22 fruit juices listed by the USDA (Haytowitz and Bhagwat, 2010). Only black raspberry juice (ORAC $=10,460$ $\mu$ moles TE/100 g wet weight) had a higher antioxidant rating. 
The freeze-dried Galaxy ${ }^{\circledR}$ ORAC value of $178.1 \mu$ moles $\mathrm{TE} / \mathrm{g}$ is approximately the same antioxidant capacity as that reported for cranberry (Sun et al., 2002) which is considered the reference standard for calculation of Biological Indices (BI). Thus, Galaxy ${ }^{\circledR}$ has a BI of 3.40 which of course is $3.40 \mathrm{X}$ higher than the cranberry standard $(\mathrm{BI}=1)$. Table 1 shows a summary of the ORAC values, EC50s, and BI for Galaxy ${ }^{\circledR}$ and several superfruits of which three (mangosteen, GAC, and Acai) are contained in this product. The BI is a useful parameter to compare the combined effects of anticancer activity and antioxidant activity. Any BI above 1 is considered relatively good. Thus, Galaxy has a good BI compared against the individual fruits. Except for mangosteen and GAC, all of these superfruits were in the same order of magnitude ranging from 1.73 to 8.46 . There was no correlation $\left(\mathrm{r}^{2}=0.07 ; \mathrm{p}=0.473\right)$ between the anticancer (EC50) parameter and the ORAC value for several superfruits suggesting that antioxidative activity may not be totally related to in vitro anticancer activity (Fig. 5). Still, a careful look at Fig. 5 shows that five of the nine samples (including Galaxy ${ }^{\circledR}$ particulates) had ORAC values above $150 \mu$ moles TE/g and an EC50 less than 1mg/mL. Thus, ORAC and EC50s values for these superfruits appear to be related, just not in a clear inverse linear fashion.

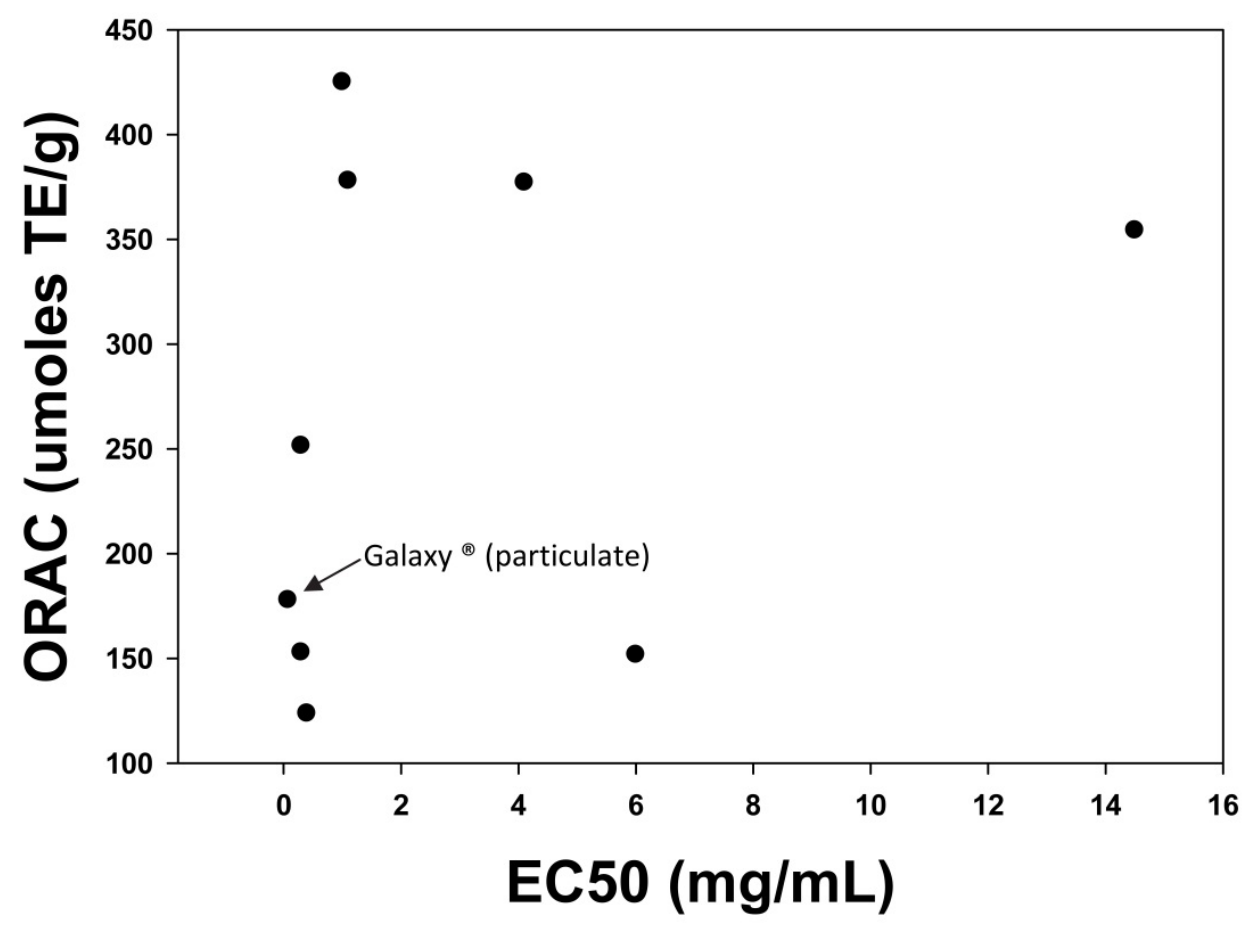

Figure 5. Plot of the relationship between ORAC values and EC50 values for Galaxy ${ }^{\circledR}$ and eight superfoods

Correlation studies on these parameters with other fruits have also been equivocal; some are positively correlated (Wang and Lewers, 2007; Faria et al., 2006) while others are not (Boivin et al., 2007). A recent review (Wang et al., 2011) demonstrated that there is no conclusive 
proof that high antioxidant activity is a good indicator of high anticancer activity but left the reader with the challenge to continue to test this hypothesis until it is unequivocally resolved one way or the other. Similar studies with total phenolics have also shown mixed results. Some studies of total phenolics contained in traditional fruit, have shown to be highly correlated with anticancer activity (Silva et al., 2006; Atmani et al., 2011) and they (phenolics) are also highly correlated with ORAC values (Atmani et al., 2011; Kalt et al., 2003). However, some researchers have shown that there is no correlation between total phenolics and anticancer activity (Thompson et al., 2009; Sun et al., 2002; Weber et al., 2001). Thus, the expected link between ORAC values and total phenolics and anticancer activity continues to be a subject of debate in the literature.

\begin{tabular}{|c|c|c|c|c|c|}
\hline Fruit & ORAC $^{a}$ & Score $^{\mathbf{b}}$ & EC50 (mg/mL) & Score $^{\mathbf{c}}$ & BI $^{\mathbf{d}}$ \\
\hline Mangosteen & 251.60 & 1.42 & 0.30 & 48.33 & 24.88 \\
\hline GAC & 153.00 & 0.86 & 0.30 & 48.33 & 24.60 \\
\hline Acai & 425.10 & 2.42 & 1.00 & 14.50 & 8.46 \\
\hline Goji & 378.10 & 2.14 & 1.10 & 13.20 & 7.67 \\
\hline Galaxy® & 178.10 & 1.00 & 2.30 & 6.30 & 3.65 \\
\hline Sea Buckthorn & 377.10 & 2.13 & 4.10 & 3.54 & 2.84 \\
\hline Noni & 151.80 & 0.86 & 5.60 & 2.59 & 1.73 \\
\hline Cranberry & 354.27 & 1.00 & 14.50 & 1.00 & 1.00 \\
\hline
\end{tabular}

a Oxygen Radical Absorption Capacity $(\mathrm{ORAC})=$ umoles TE/g freeze-dried product

${ }^{\mathrm{b} S}$ core for total antioxidant activity $=$ sample ORAC value/cranberry total antioxidant activity

cScore of antiproliferative activity = cranberry EC50 value/sample EC50 value

$\mathrm{d} B \mathrm{I}=$ score of total antioxidant activity + score of antiproliferative activity $/ 2$

Table 1. Summary of the total antioxidant activity (ORAC), antiproliferative (EC50), and the ranked Bioactivity Index (BI) for Galaxy ${ }^{\circledR}$ and seven superfruits; mangosteen, acai, goji, and cranberry are found in Galaxy found in Galaxy ${ }^{\circledR}$ compared against the cranberry standard.

Fig. 6 shows the in vitro effect of Galaxy ${ }^{\circledR}$ straight (raw product) on MDA-MB-231 breast cancer cells. Galaxy ${ }^{\circledR}$ has an EC50 $=2.3$ which is an order of magnitude lower (more cytotoxic) than most traditional fruits (Weber et al., 2001) but higher (less cytotoxic) than most chemotherapy drugs (Frankfurt and Krishan, 2003).

Figs. 7 and 8 show the in vitro dose-response curve for the effect of the Galaxy ${ }^{\circledR}$ supernatant and particulate fractions respectively on breast cancer cell line MDA-MB-231. It is clear that 
the supernatant (Fig. 7: EC50=3.4) and the particulate fraction (Fig. 8: EC50=0.075 mg/mL) were both cytotoxic to this cell line, but the particulate fraction was 47X more toxic than the supernatant fraction. This indicates that most of the phytochemicals (98\%) in Galaxy® contributing to the anticancer activity are membrane-bound. These data are in contrast to those reported by Wang et al. (1996) who found less than $10 \%$ of the ORAC activity in a wide variety of different fruit pulp or particulates; they found most of the bioactivity in the extracted juice. However, the USDA ORAC database (Haytowitz and Bhagwhat, 2010) apparently also showed that most of the antioxidant activity in a number of fruits was associated with the pulp, and not the juice.

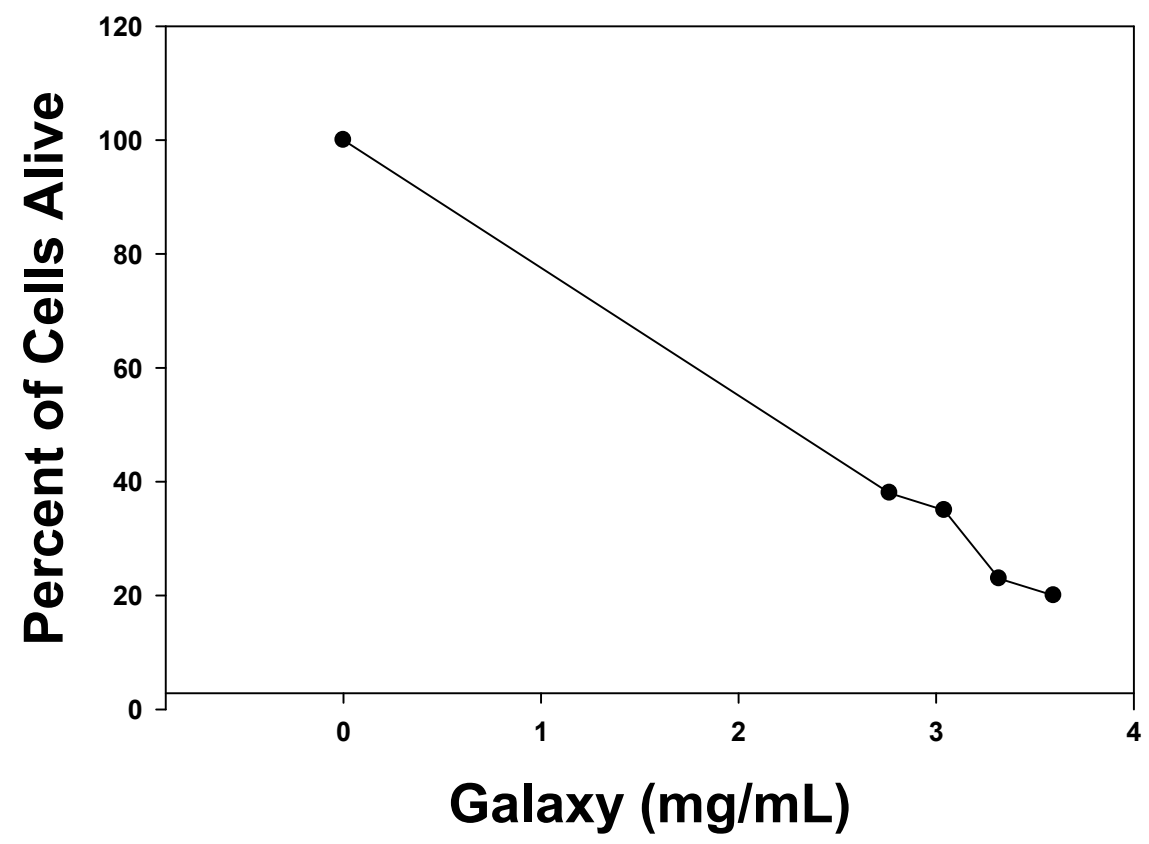

Figure 6. Galaxy ${ }^{\circledR}$ (straight from container) effect on MDA-MB-231 breast cancer Cells (EC50=2.3 $\mathrm{mg} / \mathrm{mL}$ ).

When the particulate dose-response curve was compared to the FDA-approved breast cancer drug Onxol ${ }^{\circledR}$ (paclitaxel), the two curves tended to track each other with both EC50s being in the same order of magnitude (Fig. 8; EC50=0.03 mg/mL for paclitaxel; EC $50=0.075$ $\mathrm{mg} / \mathrm{mL}$ for the Galaxy® particulates). The EC50 for paclitaxel in our study was in the same order of magnitude as that reported by Danhier et al. (2009) for HeLa cells, but higher than that reported by Yu et al. (2004) for MCF-7 and MDA-MB-231 cell lines. 


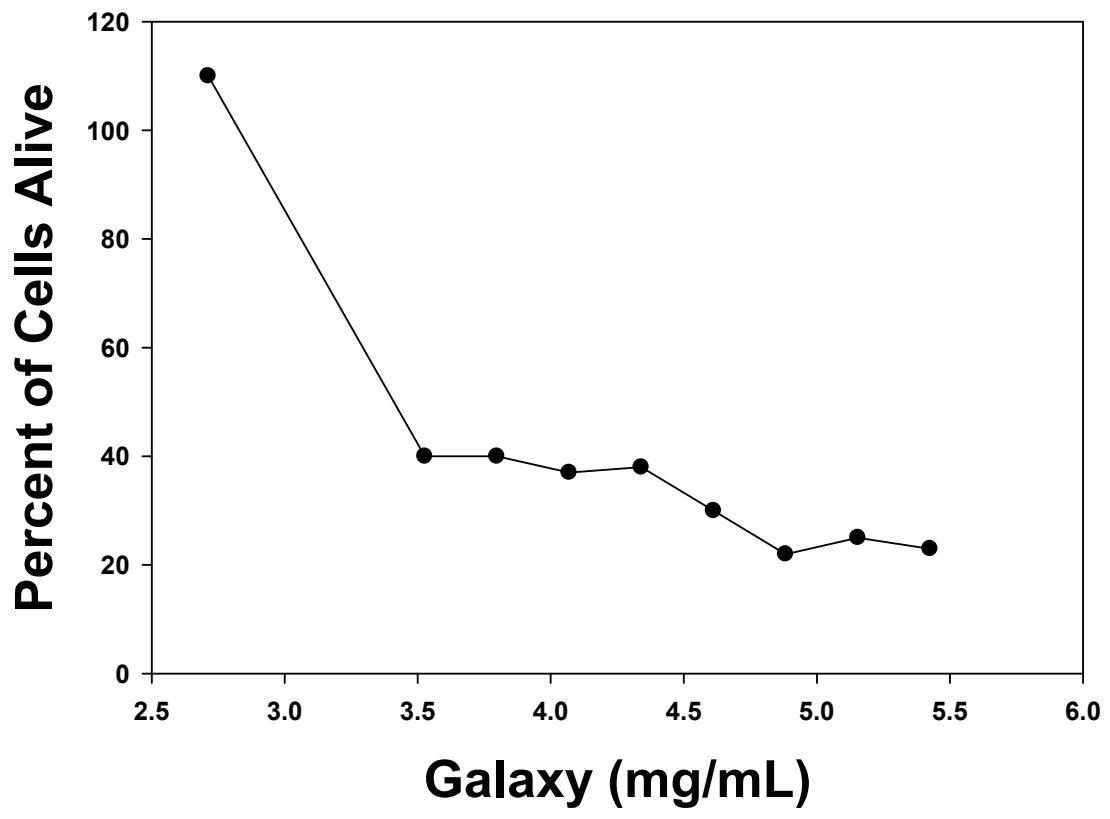

Figure 7. Galaxy ${ }^{\circledR}$ (supernatant) toxicity to MDA-MB-231 Human Breast Cancer Cells $(\mathrm{EC} 50=3.4)$.

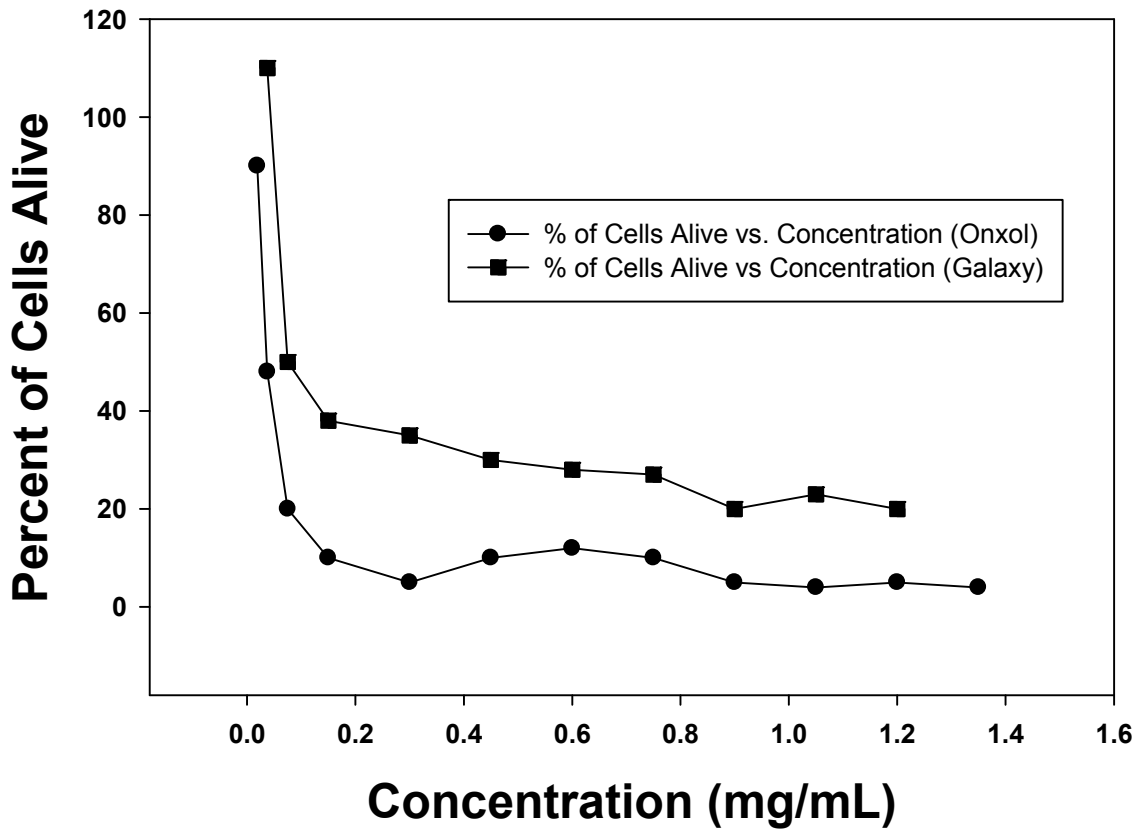

Figure 8. Comparison of Galaxy® Particulates and Onxol® (FDA approved drug) against Human Breast Cancer Cell Line MDA-MB-231 (Galaxy® EC50 = 0.075 mg/mL; Onxol® EC50 = 0.03 mg/mL). 
We have also tested Galaxy® against several other human cancer cell lines and calculated a Selectivity Index (SI) which compares EC50s of cancer cells and normal cells. Table 2 summarizes the EC50s and ranked (SI) for various samples of Galaxy ${ }^{\circledR}$ on breast cancer, lung cancer, and liver cancer compared to its effect on normal tissues. The higher the SI values, the higher the selectivity of Galaxy ${ }^{\circledR}$ against cancer cells compared to the normal tissues. Any SI above 2 is considered a reasonably selective SI (Basida et al., 2009). Note that the SI values for Galaxy ${ }^{\circledR}$ ranged from 3.2 (for lung cancer) to over 370 for the particulate fraction. Badisa et al. (2009) reported that pure anticancer compounds (piperidinyl-DES, Pyrrolidinyl-DES, and 4-hyroxy tamoxifen) had SI values that ranged from 1.29 to $>2.84$. They further indicated that an SI value less than 2 probably indicates general toxicity of pure compounds (Koch et al., 2005). Thus, one of their three compounds, pyrrolidinyl-ES showed a high degree of cytotoxic selectivity, while 4-hydroxy tamoxifen (an anti-breast-cancer drug) showed an SI of less than 2 suggesting general toxicity to cells according to the recommendation of Koch et al.(2005).

\begin{tabular}{|c|c|c|c|c|}
\hline Cell Line & Cell Type & Galaxy Sample & EC50 (mg/mL) & SI* $^{*}$ \\
\hline MDA-MB-231 & Breast cancer & Particulates & 0.075 & 371 \\
\hline & Breast cancer & Unfractionated & 2.30 & 12 \\
\hline Hs578Bst & Normal breast cells & Freeze-dried & 27.80 & 8 \\
\hline HepG2 & Liver cancer & Freeze-dried & 3.44 & 3.5 \\
\hline THLE-3 & Normal hepatocytes & Freeze-dried & 11.99 & - \\
\hline A-549 & Lung cancer & Freeze-dried & 6.20 & 3.20 \\
\hline MRC-5 & Normal lung cells & Freeze-dried & 19.68 & - \\
\hline
\end{tabular}

*SI $=$ EC50 on normal tissue/EC50 on cancer cells

Table 2. Summary of the EC50s and ranked Selectivity Indices (SI) for Galaxy® samples on human breast cancer, lung cancer, and liver cancer compared to normal human tissues.

In addition, Al-Qubaisi et al. (2011) reported an SI of 7.6 for liver cell comparisons using Goniothalamin isolated from a plant compared to Galaxy ${ }^{\circledR}$ 's SI of 3.5; however, Galaxy ${ }^{\circledR}$ was over 1,700X less toxic to normal liver cells when the EC50s of Galaxy ${ }^{\circledR}$ and Goniolthalamin were compared. Apparently, phytotherapy (using mixtures of dozens of fruit-based and vegetable-based polyphenols and other antioxidants such as those found in Galaxy ${ }^{\circledR)}$ are often less toxic than the purified compounds used in mainstream cancer 
therapy. Indeed, Krishna et al. (2009) has suggested that no anti-neoplastic drug is devoid of side effects which includes the widely used anti-cancer drug, paclitaxel. Our in vitro data suggests that the phytochemicals found in Galaxy® are quite selective for cancer cells. While these preliminary data on Galaxy ${ }^{\circledR}$ are encouraging, the authors caution all readers to not extrapolate conclusions from the in vitro data to what might happen in large randomized double-blind in vivo investigations.

Figs. 9-12 summarizes the dose-responses curves of freeze-dried Galaxy® on colon cancer, prostate cancer, lung cancer, and liver cancer. The EC50s ranged from about 4.0-11 mg/mL which is an order of magnitude higher in cytotoxicity (lower EC50) than that reported for four raspberry varieties and one apple variety (Weber et al., 2001) and for a variety of other fruits (Sun et al., 2002). Thus, Galaxy ${ }^{\circledR}$ seems to have a broad-spectrum of in vitro antiproliferative and antioxidant activities. However, it is still not known if or how the individual components in the product interact to produce these toxicities.

Three hundred and eight senior athletes had their baseline blood glucose levels taken, then drank $30 \mathrm{~mL}$ of Galaxy ${ }^{\circledR}$, and then waited about one hour and had their blood glucose taken again (post-treatment). The data show that Galaxy ${ }^{\circledR}$ apparently does not spike blood glucose (Table 3) which is probably a result of the balance of simple sugars found in the product (Fig. 13) which was $16.5 \%$ xylitol; $42.2 \%$ fructose; and $41.3 \%$ glucose. Galaxy® also contains nine essential amino acids.

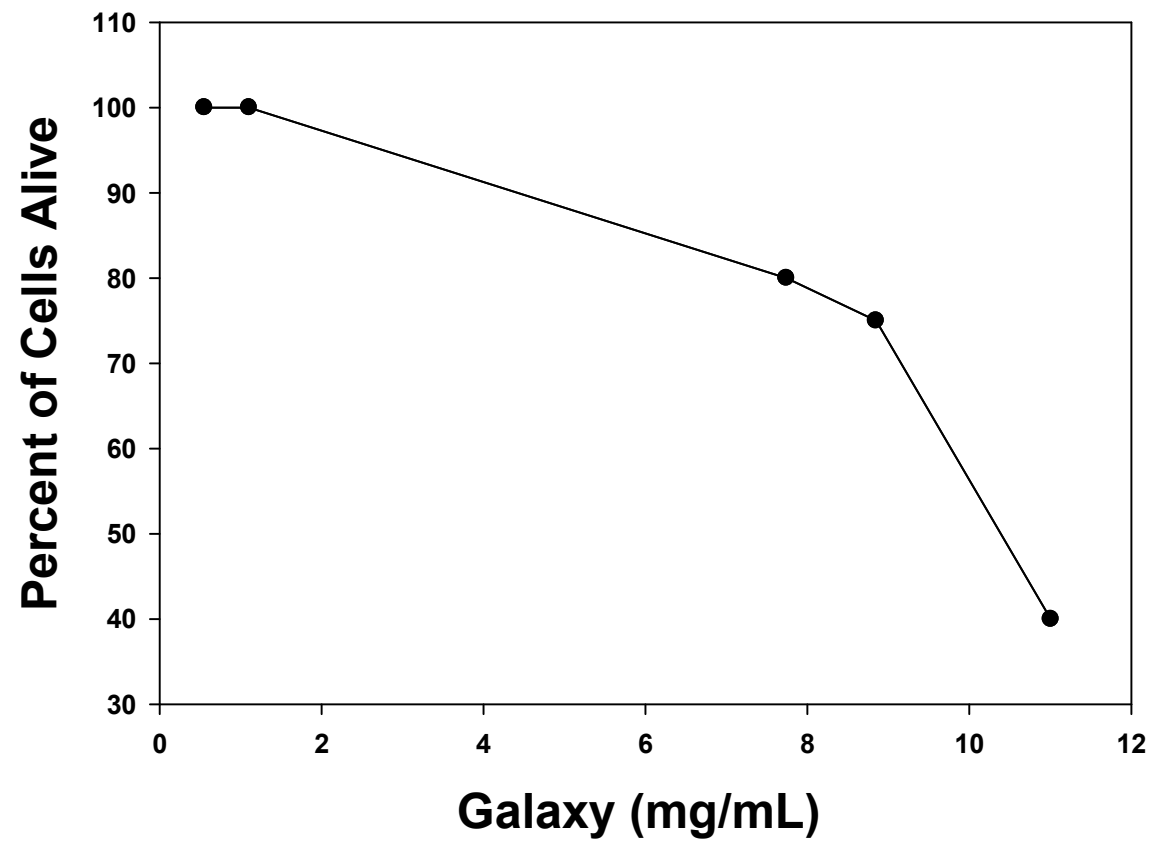

Figure 9. Effect of Freeze-dried Galaxy ${ }^{\circledR}$ on Human Colon Cancer Cells $(E C 50=10.5 \mathrm{mg} / \mathrm{mL})$. 


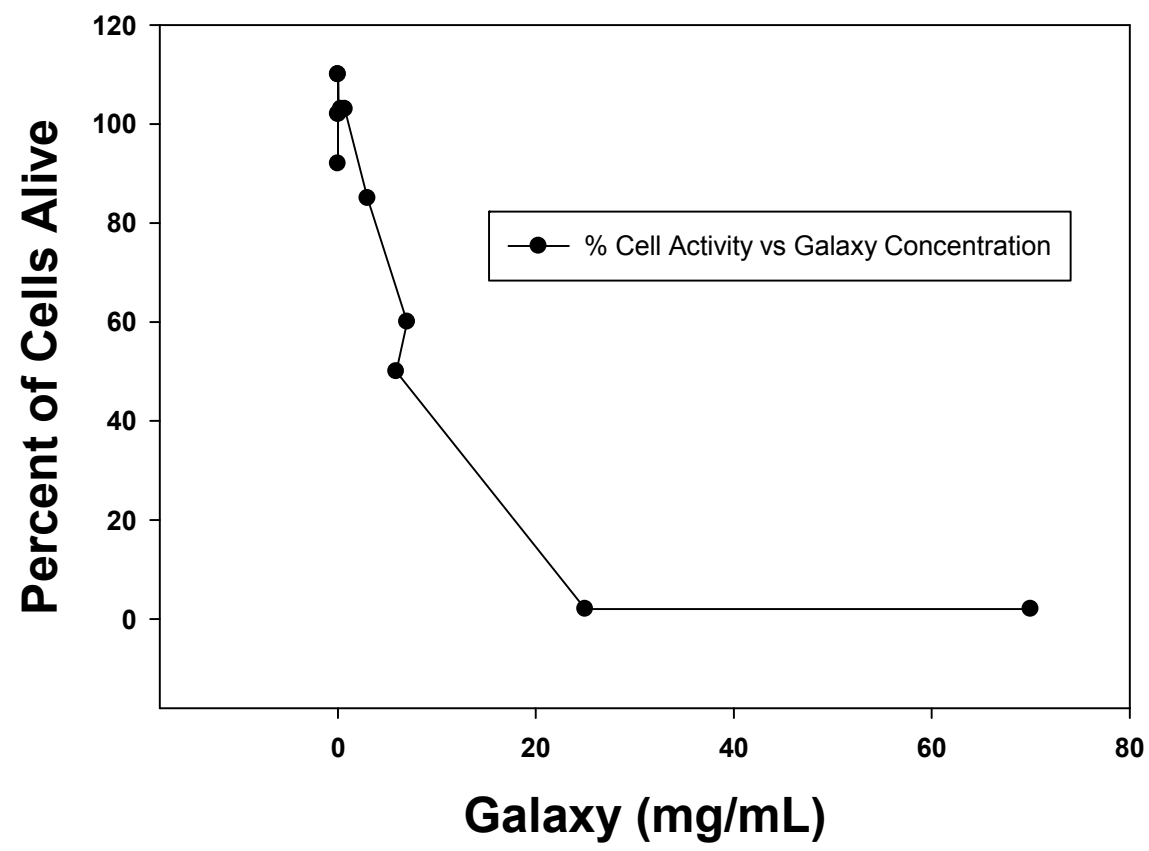

Figure 10. Effect of Freeze-dried Galaxy® on DU 145 Human Prostate Cancer Cells (EC50 =5.3 mg/mL).

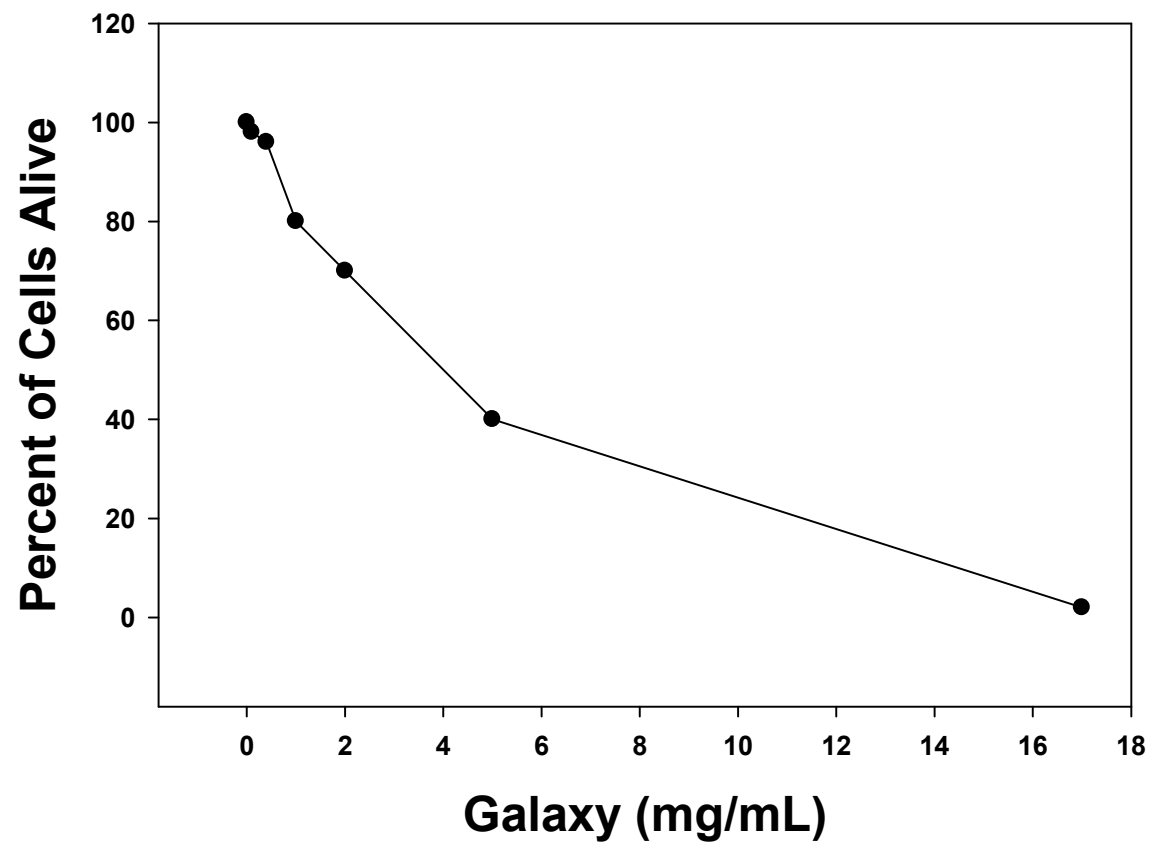

Figure 11. Effect of Freeze-dried Galaxy ${ }^{\circledR}$ on A-549 Human Lung Cancer Cells (EC50 = 5.0 mg/mL). 


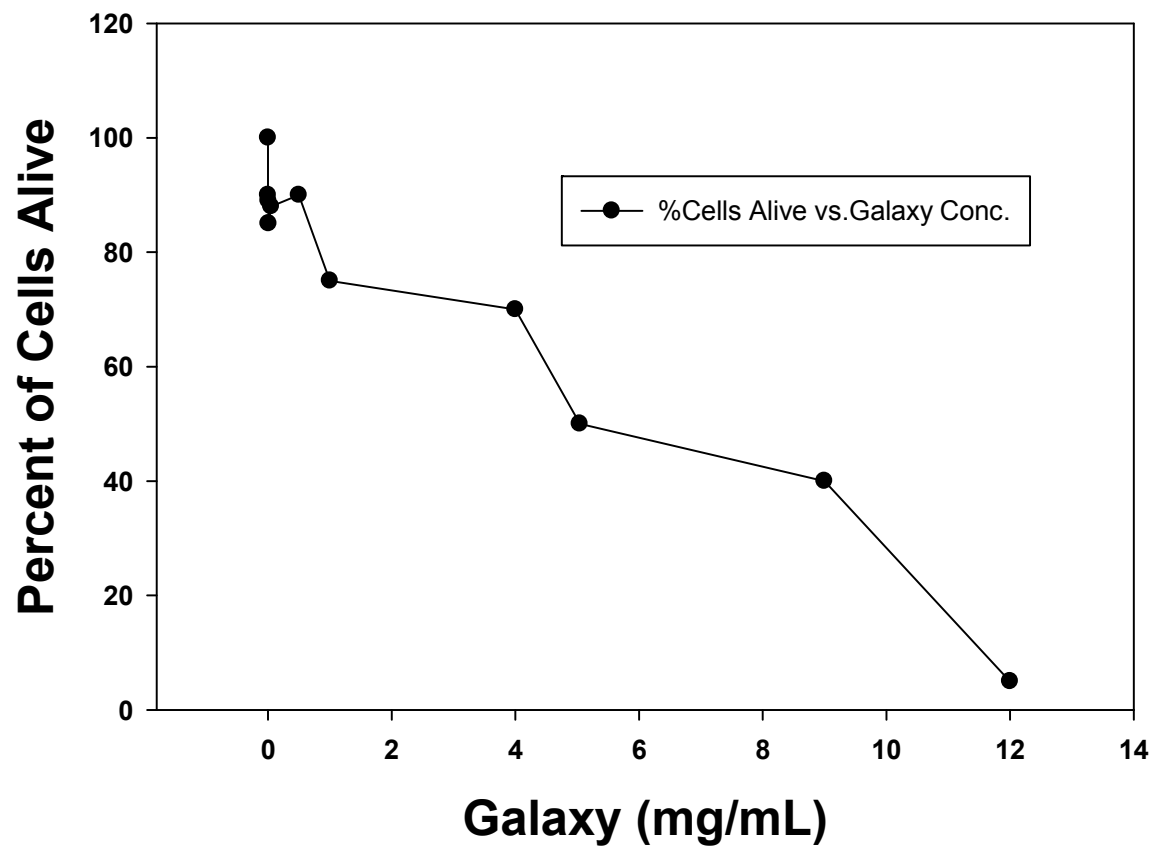

Figure 12. Effect of Freeze-dried Galaxy® ${ }^{\circledR}$ on HepG2 Human Liver Cancer Cells (EC50 = 5.0 mg/mL).

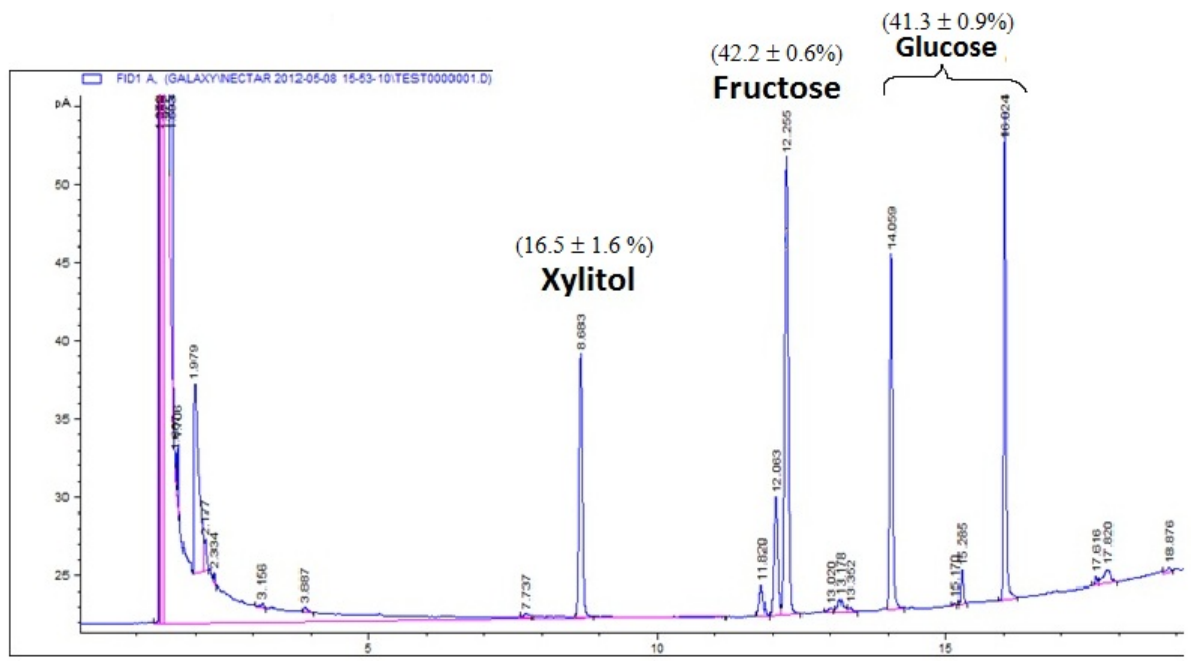

Figure 13. Chromatogram of the types of natural sugar in Galaxy ${ }^{\circledR}$.

JoyLife International does not make health claims for their product because it is marketed as a nutritional supplement, not as a medicine. However, we do have one data set on a 33 year old Caucasian female who suffers from Acute Lymphocytic Leukemia (ALL) who agreed to 
take the product for seven months without any other medical intervention, e.g. no chemotherapy. This was done under the strict supervision of her health-care providers. Fig. 14 shows that her white blood cell count dropped from 68,000 to 21,700 cells/ $\mu \mathrm{L}$, coupled with a substantial improvement of her secondary health parameters associated with the disease (e.g., lethargy, bruising, muscular weakness, etc). This resulted in a $68 \%$ drop in the WBC over the seven month treatment period. The regression $\left(\mathrm{r}^{2}=0.77\right)$ relationship between the seven-month Galaxy ${ }^{\circledR}$ treatment and changes in WBC suggests that $77 \%$ of the variability in the changes in the slope of the graph was likely due to the Galaxy® treatment. The authors are not drawing any conclusions from this single data set, nor should the reader, but it is provided since it was done under the close scrutiny and supervision of her oncologists and without any other intervention. This study is on-going.

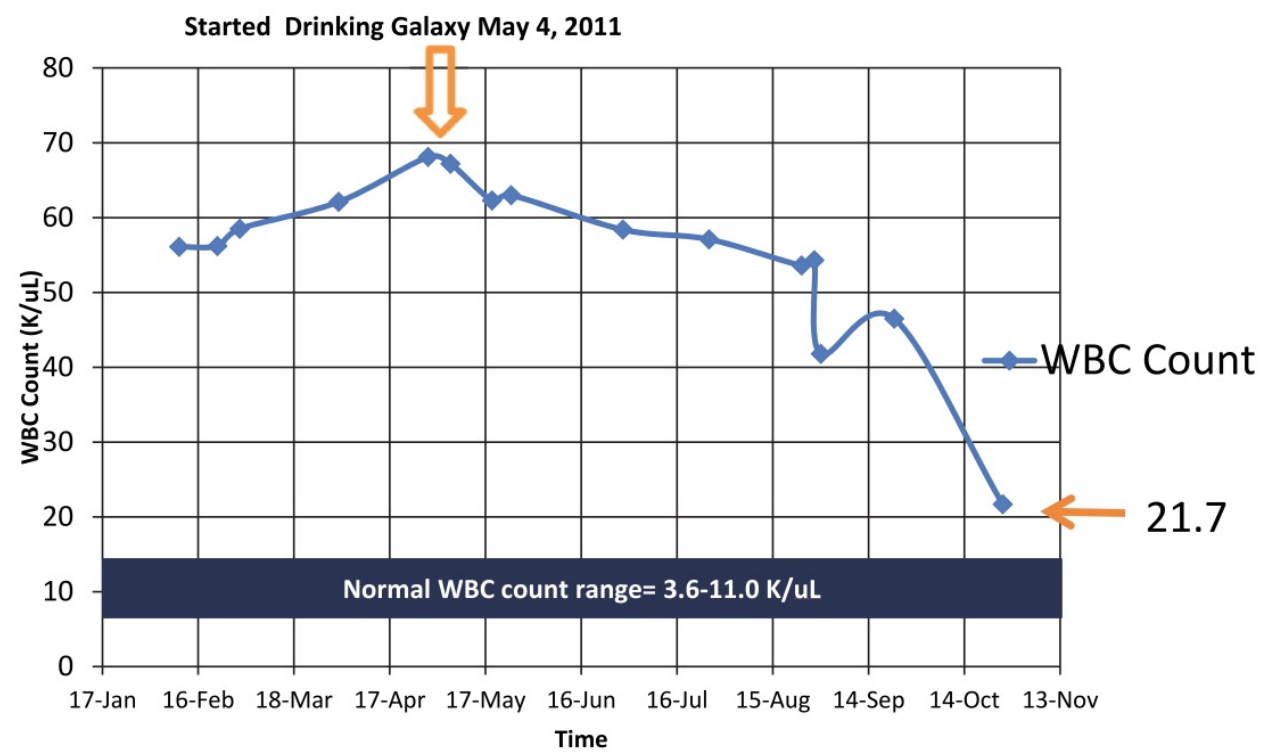

Figure 14. Effect of Galaxy® on WBC Count in an Acute lymphocytic Leukemia Patient

\section{Summary and conclusions}

Galaxy ${ }^{\circledR}$ is a nutritional food blend that contains 32 bioactive components including thirteen high antioxidant fruits. A freeze-dried sample of this blend has an ORAC score of $178.10 \pm 3.1 \mu$ moles TE/ $\mathrm{g}$ of freeze-dried product or $35.6 \mu$ moles TE/g fresh product. Based on a dose of $30 \mathrm{~mL} /$ day, a person would consume 1068 ORAC units/dose. This value represents $21-36 \%$ of the daily recommended ORAC units (3000-5000 ORAC units/day) suggested by the USDA. Thus, the entire bottle of Galaxy ${ }^{\circledR}$ contains about 26,700 ORAC units. It is likely that the antioxidants contained in this product contributed to the in vitro anticancer activity. These anticancer EC50s ranged from 0.075 to $11 \mathrm{mg} / \mathrm{mL}$ on breast, colon, prostate, lung, and liver cancers. The raw product, the supernatant, and 
particulate fractions of Galaxy ${ }^{\circledR}$ were all bioactive, although the particulate fraction was over 40X more active than either the raw product or supernatant suggesting that about $98 \%$ of the bioactivity is contained in the particulate fraction. In fact, the particulate fraction dose-response curve tracked the dose-response curve of Onxol ${ }^{\circledR}$ (an FDAapproved drug for breast cancer) with EC50s (EC50 $=0.075 \mathrm{mg} / \mathrm{mL}$ for Galaxy ${ }^{\circledR}$ particulates and $\mathrm{EC} 50=0.03 \mathrm{mg} / \mathrm{mL}$ for Onxol®) that were in the same order of magnitude of each other.

There was a no correlation between the anticancer activity (EC50s) and the ORAC values of the 9 superfruits investigated (four of which are found in the product) $\left(r^{2}=0.0758 ; p=0.473\right.$ ), although four of the nine superfruits (including Galaxy ${ }^{\circledR}$ ) had an EC50 < 1.0 and ORAC values greater than 150 umoles TE/g. From these data, it appears that ORAC units may somehow still be connected, though it is apparently not a clear inverse relationship. Galaxy ${ }^{\circledR}$ was also shown to have a Bioactivity Index (BI) of 3.40, which was 3.40X more active than the cranberry BI reported in the literature.

Galaxy ${ }^{\circledR}$ additionally did not spike blood glucose levels of 308 participants during the $1 \frac{1}{12}$ hours following the normal dose of $30 \mathrm{~mL}(\mathrm{n}=308)$. This was likely due to the balance of simple sugars found in the product: $16.5 \%$ xylitol; $42.2 \%$ fructose; and $41.3 \%$ glucose (Fig. 13). In addition, Galaxy ${ }^{\circledR}$ contains nine essential amino acids.

JoyLife International makes no health claims for this product because it is marketed as a nutritional supplement, not a medicine; however, in cooperation with her physician, one patient with ALL showed a 68\% drop in WBC count (from 68,000/uL to 21,700/uL) after seven months post-treatment with Galaxy ${ }^{\circledR}(30 \mathrm{~mL} /$ day) without any other medical interventions including chemotherapy. In addition, there were significant qualitative improvements in the patient's secondary health parameters. This study is on-going.

Research has clearly shown that people in the U.S. are not eating enough vegetables, since only $2 \%$ of TAC consumed in any form comes from vegetables.

These data have suggested other experiments that need to be considered. For example, investigations are needed to determine how these cancer cells are dying, i.e., by apoptosis or necrosis as well as the toxicological contribution of each of the individual components of the blend. The issue of possible synergistic activity among the ingredients also needs further study. The effect of Galaxy ${ }^{\circledR}$ on rodent models with induced inflammatory diseases need to also be considered. And finally, larger randomized double-blind experiments are needed to validate the data from the ALL patient and from other people suffering from chronic diseases.

\section{Author details}

Gary M. Booth*

Brigham Young University, Department of Plant and Wildlife Sciences, Provo, Utah, USA

${ }^{*}$ Corresponding Author 
Tory L. Parker

Brigham Young University, Department of Nutrition, Dietetics, and Food Science, Provo, Utah, USA

Christopher M. Lee

Research for Cancer Care Northwest and Gamma Knife of Spokane,

Department of Radiation Oncology at the University of Washington, Spokane, WA, USA

\section{Acknowledgement}

The authors are not associated with the sale, marketing, or distribution of Galaxy®. All of the data were generated from protocols developed by the principal investigators without contact with the company. All of the data contained in this manuscript has not been submitted to any other publisher.

\section{References}

Al-Qubaisi, M., R. Rozita, S-K. Yeap, A-R Omar, A-M Ali, and N.B. Alitheen. 2011. Selective cytotoxicity of Goniothalamin against hepatoblastoma HepG2 cells. Molecules 16:2944-2959.

Atmani, Dina., M. Begna Ruiz-Larrea, J.I. Ruiz-Sanz, L.J. Lizcano, F. Bakkali, and Djebbar Atmani. 2011. Antioxidant potential, cytotoxic activity and phenolic content of Clematis flammula leaf extracts. J. Med. Pl. Res. 5(4):589-598.

Badisa, R.B., S.F. Darling-Reed, P. Joseph, J.S. Cooperwood, L.M. Latinwo, and C.B. Goodman. 2009. Selective cytotoxic activities of two novel synthetic drugs on human breast carcinoma MCF-7 cells. Anticancer Res. 29:2993-2996.

Balick, Michael J. and Paul Alan Cox. 1996. Plants, People, and Culture. Scientific American Library: New York.

Block, G., B. Patterson, and A. Subar. 1992. Fruit, vegetables, fruit, and cancer prevention: a review of the epidemiological evidence. Nutr. Cancer 18:1-29.

Boivin, D., M. Blanchette, S. Barrette, A. Moghrabi, and R. Beliveau. 2007. Inhibition of cancer cell proliferation and suppression of TNF-induced activiation of NFkB by edible berry juice. Anticancer Res. 27:937-948.

Capua, C., N.P. Hopson, M.M. Stewart, G. Robert Johnston, K.L. O’Neil, G. B. Schaalje, C.M. Lee, and G.M. Booth. 2010. Cytotoxicity of Atriplex confertifolia. J. Toxicol. 2010:Article ID 976548, 7 pages. Doi:10.1155/2010/976548.

Danhier, F., N. Lecouturier, B. Vroman, C. Jerome, J. Marchannd-Brynaert, O. Feron, and V. Preat. 2009. Paclitaxel-loaded PEGylated PLGA-based nanoparticles: In vitro and in vivo evaluation. J. Control. Rel. 133:11-17.

Faria, A., C. Calhau, V. Freitas, and N. Mateus. 2006. Procyanidins as antioxidants and tumor cell growth modulators. J. Agric. Fd Chem. 54:2392-2397.

Ferguson, P. J., E. Kurowska, D. J. Freeman, A. F. Chambers, and D. J. Koropatnick. 2004. A flavonoid fraction from cranberry extract inhibits proliferation of human tumor cells. J. Nut. 134(6):1529-1535. 
Frankfurt, O.S. and A. Krishan. 2003. Apoptosis-based drug screening and detection of selective toxicity to cancer cells. Anti-Cancer Drugs. 14(7):555-561.

Haytowitz, D.B. and S. Bhagwat. 2010. USDA database for the oxygen radical absorbance capacity (ORAC) of Selected foods, Release 2. Nutrient Data Laboratory, Beltsville Human Nutrition Research Center (BHNRC), Beltsville, MD.

Guthrie, N. and K.K . Carrol. 1998. Inhibition of human breast cancer cell growth and metastasis in nude mice by citrus juices and their constituent flavonoids. Packer, L. and A.S.H. Ong. Eds. Biological Oxidants and Antioxidants. Molecular Mechanisms and Health Effects. 1998:310-316. AOCS Press. Champaign, IL.

Kalt, W., C. Lawand, D.A.J. Ryan, J.E. McDonald, H. Donner, and C.F. Forney. 2003. Oxygen radical absorbing capacity, anthocynanin and phenolic content of highbush blueberries (Vaccininium corymbosum L.) during ripening and storage. J. Amer. Hort. Sci. 128(6):917923.

Koch, A., P. Tamez, J. Pezzuto, and D. Soejarto. 2005. Evaluation of plant used for antimalarial treatment by the Massai of Kenya. J. Ethnopharmacol. 101:95-99.

Krishna, I.V., G.R. Vnaja, N.S. Kumar, and G. Suman. 2009. Cytotoxic studies of antineoplastic drugs on human lymphocytes-in vitro studies. Cancer Biomark. 5(6):261262.

Liu, R.H. 2004. Potential synergy of phytochemicals in cancer prevention: mechanism of action. J. Nutr. 134:3479S-3485S.

Mertens-Talcott, S.U., S.T. Talcott, and S.S. Percival. 2003. Low concentrations of quercetin and ellagic acid synergistically influence proliferation, cytotoxicity and apoptosis in MOLT-4 human leukemia cells. J. Nutr. 133:2669-2674.

Parker, T.L., X-H. Wang, J. Pazimino, and N.J. Engeseth. 2007. Antioxidant capacity and phenolic content of grapes, sun-dried raisins, and golden raisins and their effect on ex vivo serum antioxidant capacity. J. Agric. Fd. Chem. 55:8472-8477.

Seeram, N.P., L.S. Adams, S.M. Henning, Y. Niu, Y. Zhang, M.G. Nair, and D. Heber. 2005. In vitro antiproliferative, apoptotic, and antioxidant activities of punicalagin, ellagic acid and a total pomegranate tannin extract are enhanced in combination with other polyphenols as found in pomegranate juice. J. Nutr Biochem. 16:360-367.

Silva, E.M., J.N.S. Souza, H. Rogez, J.F. Rees, and Y. Larondelle. 2006. Antioxidant activities and polyphenolic contents of fifteen selected plant species from the Amazonian region. Food Chem. 101: 1012-1018.

Steinmetz, K.A. and J.D. Potter. 1991. Vegetables, fruit, and cancer. I. Epidemiology. Cancer Causes Control 2:325-357.

Sun, Jie, Yi-Fang Chu, Xianzhong Wu, and Rui Hai Liu. 2002. Antioxidant and antiproliferative activities of common fruits. J. Agric. Fd Chem. 50:7449-7454.

Thompson, M.D. 2009. Chemical composition and mammary cancer inhibitory activity of dry bean. Crop Sci. 49(1):179-186.

USDA Human Research Center on Aging. Feb. 1999. “Can foods forestall aging?” Agri. Res. Feb. 1999.

Wang, Hong, Guohua Cao, and Ronald L. Prior. 1996. Total antioxidant capacity of fruits. J. Agric. Fd Chem. 44(3):701-705. 
Wang, S., K.A. Meckling, M.F. Marcone, Y. Kakuda, and R. Tsao. 2011. Can phytochemical antioxidant rich foods act as anti-cancer agents? Food Res. Intern. 44:2545-2554.

Wang, S.Y. and K.S. Lewers. 2007. Antioxidant activities and anticancer cell proliferation properties of wild strawberries. J. Amer. Soc. Hort. Sci. 132:647-658.

Weber, C., M. Liu, X.Q. Li, and R. H. Liu. 2001. Antioxidant capacity of anticancer properties of red raspberry. NY Fruit Quart. 9(3): 13-15.

Yang, Meng, Sang-Jin Chung, Chin Eun Chung, Dae-Ok Kim, Won O. Song, Sung I. Koo, and Ock K. Chun. 2011. Estimation of total antioxidant capacity from diet and supplements in US adults. Brit. J. Nut. 106:254-263.

Zhou, J.R., L. Yu, Y. Zhong, and G.L. Blackburn. 2003. Soy phytochemicals and tea bioactivity components synergistically inhibit androgen-sensitive human prostate tumors in mice. J. Nutr 133:516-521. 